\title{
OFICINAS PEDAGÓGICAS COMO PROPOSTA PARA UM ENSINO DE FÍSICA DIFERENCIADO E INOVADOR
}

\section{PEDAGOGICAL OFICINES AS A PROPOSAL TO A DIFFERENTIATED AND INNOVATIVE PHYSICS TEACHING}

Isabella Helanny Costa Gomes ${ }^{1}$; Dandelson Darlan Alves de Carvalho²; Antônio Raimundo Alves da Costa ${ }^{3}$; Teresinha Vilani Vasconcelos de Lima ${ }^{4}$

\section{INTRODUÇÃO}

Atualmente, o ensino e aprendizagem de Física vêm enfrentando grandes dificuldades, esse fato é percebido nas concepções dos alunos do ensino médio sobre a disciplina de Física, segundo (Ricardo; Freire, 2007), que mostram que os mesmos não gostam da disciplina devido à grande quantidade de cálculos e à falta de relação com o cotidiano. Um dos motivos que levam os alunos, a olharem a Física dessa forma é a maneira como essa disciplina é a eles apresentada, com uma abordagem puramente matematizada, sem relação com o cotidiano e que, só acabam por consolidar uma visão equivocada da disciplina. Quando esse comportamento avesso à disciplina não é reforçado pelo próprio professor de Física. Assim conforme (Lima, 2011), os alunos aprendem desde cedo que as leis da Física são expressas através de fórmula matemática, ao invés de aprenderem que a matemática é apenas uma ferramenta para quantificar algumas varáveis Físicas.

Mas como ensinar Física nos dias atuais? Como os alunos aprendem? Estudos mostram que para haver construção do conhecimento o aluno precisa participar de forma ativa e efetiva no processo de ensino-aprendizagem, conforme (Santos, 2004) o saber se constrói na interação, na troca de experiências, no ouvir reflexivo e inquiridor, no debate de ideias, enfim, no diálogo, na participação.

Faz-se necessário então trabalhar com novas estratégias pedagógicas para o ensino de Física. Assim, uma alternativa é trabalhar com oficinas pedagógicas, uma vez que a mesma possibilita um maior envolvimento do aluno, pois a mobilização de saberes diante dessa atividade possibilita um processo de ensino, segundo (Freire, 1996), ensinar não é transferir conhecimento, mas criar possibilidades para a sua própria produção ou a sua construção.

No espaço da oficina, os alunos podem aprender junto com os outros, como nos afirma (Candau, 2011), as oficinas pedagógicas constituem uma estratégia metodológica baseada na articulação teoria-prática, que empregam diferentes linguagens, promove o diálogo entre os diversos saberes e conhecimentos, usa técnicas participativas e favorece a construção coletiva. O estudo da Física, para uma maior compreensão por parte dos alunos, depende das condições da prática pedagógica, da articulação entre os processos teóricos e metodológicos, diminuindo 
a importância da aplicação da linguagem matemática e aproximando o aluno da Física enquanto ciência experimental e com implicações na sua vida diária.

A abordagem experimental no espaço das oficinas pedagógicas cria situações que privilegiam as condições de aprendizagem, por refletir e rever conceitos a respeito dos fenômenos físicos, podendo avançar no aprendizado, permitindo efetuar assim, uma reestruturação de seus modelos explicativos dos fenômenos. Os experimentos são instrumento motivador para o aprendizado, pois instigam os alunos a utilizarem suas habilidades teóricas e práticas numa assimilação dos conteúdos em sala de aula, segundo (Araújo, Abib, 2003). A intenção de experimentar novas metodologias para o ensino de Física nos permitiu perceber a potencialidade do uso dos experimentos dentro das oficinas pedagógicas.

\section{RELATO DE EXPERIÊNCIA}

A experiência da realização da oficina pedagógica foi uma atividade realizada dentro da disciplina de Didática do Ensino de Física, pelos graduandos do V módulo, do curso de Licenciatura em Física. Os participantes da oficina foram 15 graduandos do I módulo do curso de Licenciatura em Física do IFPI - Campus Teresina Central. Com o objetivo de abordar os conteúdos de Física de forma dinâmica e diferenciada com experimentos, levando-os a participarem de todo o processo de construção do conhecimento de forma ativa e efetiva.

A oficina pedagógica dividiu-se em três etapas:

I Etapa - Avaliação diagnóstica para identificação do conteúdo de maior dificuldade apresentado pelos alunos.

II Etapa - Planejamento de uma oficina sobre o conteúdo de maior dificuldade, que neste caso foi o Movimento Circular (MC).

III Etapa - Desenvolvimento da oficina pedagógica em 4 horas, distribuídas em três momentos: abordagem teórico prática dos conteúdos na construção de experimentos, estudo da relação da aplicação do MC na vida diária auxiliado por vídeos e a socialização dos experimentos e conhecimentos adquiridos durante a oficina.

\section{CONSIDERAÇÕES}

A oficina pedagógica como proposta para um aula de Física diferenciada é relevante uma vez que não apresenta a disciplina de Física aos alunos apenas com fórmulas e números, mas possibilita uma interação com o conteúdo estudado através da relação teórico prática, criando possibilidades para o desenvolvimento de competências como investigar, questionar, refletir sobre o desenvolvimento científico e debater ideias. 
A oficina pedagógica também nos permite observar que é possível proporcionar metodologia de ensino da Física diferenciada e inovadora, colocando o aluno como centro do processo de construção do conhecimento, levando-o a participar de forma ativa durante o processo. Assim como também, no espaço da oficina a interação, a externalização de pontos de vista, a aprendizagem coletiva e participativa promoveu aprendizagem significativa dos conteúdos de Física.

Diante do que pudemos observar no desenvolvimento da oficina, é possível utilizar essa metodologia, incorporá-la na prática docente da forma adequada, para assim proporcionar aos alunos uma atividade diferenciada para aquisição dos conceitos, fugindo das aulas apenas teóricas, ou da forma que melhor se encaixar na práxis do professor.

\section{REFERÊNCIAS}

ARAÚJO, M. S. T; ABIB, M. L. V. S. Atividades experimentais no ensino de física: diferentes enfoques, diferentes finalidades. Revista Brasileira de Ensino de Física, [online]. 2003, vol.25, n.2, ISSN 1806-1117.

CANDAU, V. M. Diferenças Culturais, Cotidiano Escolar e Práticas Pedagógicas. Vera Maria Candau. Currículo sem Fronteiras, [s.1.], v. 11, 2011.

FREIRE, P. Pedagogia da Autonomia. Saberes Necessários à Prática Educativa. $1^{\mathrm{a}}$ edição ed. São Paulo.

LIMA, F. D. A. As disciplinas de física na concepção dos alunos do ensino médio na rede pública de Fortaleza/CE. 2011. [s.1.], 2011.

RICARDO, E. C.; FREIRE, J. C. A. A concepção dos alunos sobre a física do ensino médio: um estudo exploratório. Revista Brasileira de Ensino de Física, [s.1.], v. 29, n.2, 2007.

SANTOS, J. C. S. Processos participativos na construção do conhecimento em sala de aula. Cáceres, MT: UNEMAT,2004. 